\title{
Identifikasi Karakteristik Peluruhan Hasil Peledakan Andesit berdasarkan Beberapa Prediktor pada Tunnel \#4 Kereta Cepat Indonesia China di Kecamatan Sukatani Kabupaten Purwakarta Provinsi Jawa Barat
}

\author{
Aghrid Salsabiela* \\ Prodi Teknik Pertambangan, Fakultas Teknik, Universitas Islam Bandung, \\ Indonesia. \\ *aghridsalsabiela@gmail.com
}

\begin{abstract}
Blasting is commonly used in the activities of the excavation of hard rock not only in mining and quarrying, but also in the tunnel construction of the subway, highway, and dam construction. (Kuzu, 2008). Activities blasting produces a negative impact on the environment is that the vibration of the ground, the formation and characteristics of different rocks in the study area lead to the difference in the value of the vibration of the ground that is produced during the activities of blasting. Methods in the analysis of vibration of the soil are influenced by the scaled distance as well as the value of peak particle velocity, the relationship of the two will produce a value of the coefficient of decay and site exponent. The parameters that affect the vibration of the ground, namely the distance, the weight of the explosives, the type of wave shakes as well as the constant decay and site exponent. Analysis of the predictive value of peak particle velocity was found that all the predictors have differences with the actual data that is small, except in the predictor IS 6922 through predictor of the value of the correlation coefficient of the highest, but basically, the value of PPV predictions produced is very much different from the data PPV actual obtained. The Data that the resulting prediction shows that the model PPV results predicted by the regression power have a value that is very close to the value PPV actual compared with the predictions by the model or predictor of the other.
\end{abstract}

Keywords: PPV, Konstanta Decay.

Abstrak. Peledakan umumnya digunakan dalam kegiatan penggalian batuan keras tidak hanya di pertambangan dan penggalian, tetapi juga di terowongan pembangunan kereta bawah tanah, jalan raya dan konstruksi bendungan. (Kuzu, 2008). Kegiatan peledakan menghasilkan dampak negatif kepada lingkungan salah satunya yakni getaran tanah, formasi dan karakteristik batuan yang berbeda di daerah penelitian menyebabkan perbedaan nilai getaran tanah yang dihasilkan selama kegiatan peledakan. Metode dalam analisis getaran tanah ini dipengaruhi oleh scaled distance serta nilai peak particle velocity, hubungan dari keduanya akan menghasilkan nilai koefisien peluruhan dan site exponent. Adapun parameter yang mempengaruhi getaran tanah yakni jarak, berat bahan peledak, jenis gelombang getar serta konstanta peluruhan dan site exponent. Dalam pengambilan data penelitian, tidak semua variasi pengaruh diukur secara berkala, untuk itu perlu adanya penentuan prediksi untuk menentukan variasi yang tidak diperhitungkan. Analisis nilai prediksi peak particle velocity didapatkan bahwa semua prediktor memiliki perbedaan dengan data aktual yang kecil, kecuali pada prediktor IS 6922 meskipun prediktor tersebut memiliki nilai koefisien korelasi tertinggi, namun pada dasarnya nilai PPV prediksi yang dihasilkan sangat jauh berbeda dengan data PPV aktual yang didapatkan. Data prediksi yang dihasilkan didapatkan bahwa model PPV hasil prediksi oleh regresi power memiliki nilai yang sangat mendekati dengan nilai PPV aktual dibandingkan dengan prediksi oleh model atau prediktor lain.

Kata Kunci: PPV, Konstanta Peluruhan. 


\section{A. Pendahuluan}

Peledakan umumnya digunakan dalam kegiatan penggalian batuan keras tidak hanya di pertambangan dan penggalian, tetapi juga di terowongan pembangunan kereta bawah tanah, jalan raya dan konstruksi bendungan. Karena kegiatan infrastruktur ini sering kali dekat dengan (bahkan sebagian besar di dalam) kawasan pemukiman, sayangnya masalah lingkungan terjadi karena getaran tanah dan ledakan udara yang disebabkan oleh peledakan. Konstruksi terowongan dengan peledakan di daerah perkotaan menciptakan getaran tanah yang mengganggu dan juga dapat menyebabkan kerusakan struktural jika bahan peledak yang digunakan dalam jumlah berlebih. (Kuzu, 2008).

Ledakan menghasilkan getaran tanah yang dapat menyebabkan kerusakan pada struktur sekitarnya. Dalam beberapa dekade terakhir, getaran tanah akibat ledakan dan penyebarannya dalam massa batuan telah menarik lebih banyak perhatian. Efek ledakan meliputi perubahan perilaku batuan yang berimplikasi pada stabilitas dan integritas struktur. (Kumar, 2016).

Tingkat getaran tanah pada suatu jarak dipengaruhi oleh muatan bahan peledak, frekuensi getaran, karakteristik batuan, kondisi lubang ledak, dan perambatan gelombang permukaan. (Kumar, 2016). Menanggapi persoalan diatas, maka perlu adanya penelitian mengenai peluruhan dari tiap masa batuan yang ada, model yang digunakan mencakup beberapa prediktor yang telat dipublikasikan sebelumnya, dan memodelkan konstanta peluruhan yang paling optimal dalam menentukan prediksi getaran.

Berdasarkan latar belakang di atas, tujuan yang dapat diambil dari penelitian ini yaitu :

1. Mengetahui parameter yang mempengaruhi tingkat getaran tanah akibat peledakan;

2. Mengetahui karakteristik peluruhan dari batuan dengan menggunakan beberapa prediktor.

\section{B. Metodologi Penelitian}

Metode penelitian yang digunakan dalam penelitian ini yaitu dengan cara pengambilan data di lapangan serta pengolahan data sehingga dapat dihasilkan suatu analisis dari kegiatan pengukuran, dan pengolahan. Data yang didapatkan dari metode yang dilakukan antara lain :

\section{Pengambilan Data}

Adapun kegiatan pengambilan data dilaksanakan dengan 2 metode yakni:

1. Metode Primer

Metode primer merupakan metode yang dilakukan dengan tahapan persiapan dan juga tahapan pengamatan, di mana tahap persiapan dilakukan dengan persiapan alat, review teori dasar dan memahami secara prosedur percobaan yang akan dilakukan. Kemudian tahap pengamatan, pada tahapan ini dilakukan proses pengamatan dan pengambilan data hasil pengamatan, seperti data geometri peledakan, koordinat lokasi peledakan, dan pemantauan getaran tanah. Kemudian tahap akhir, pada tahapan ini dilakukan pengolahan data secara keseluruhan dan selanjutnya diolah kemudian dapat menghasilkan suatu analisis berupa prediksi getaran tanah.

2. Metode Sekunder

Metodologi penelitian sekunder dilakukan melalui studi literatur berupa jurnal dan laporan terdahulu, studi peta dasar yaitu peta topografi, peta geologi.

\section{Pengolahan Data}

Pengolahan data dilakukan untuk mendapatkan informasi lebih dari data yang sudah didapatkan sebelumnya melalui pengambilan data di lapangan atau studi literatur, adapun pengolahan data dilakukan untuk mendapat nilai scaled distance, dan peak particle velocity, koefisien peluruhan, site exponent dan koefisien kolerasi.

\section{Teknik Analisis Data}

Adapun kegiatan analisis data yang dilakukan dari hasil pengolahan data, sebagai berikut :

1. Menganalisis parameter yang mempengaruhi getaran tanah akibat peledakan;

2. Menganalisis hubungan antara scaled distance dan peak particle velocity;

3. Menganalisis hubungan antara PPV aktual dan PPV hasil prediksi. 


\section{Kesimpulan}

Kesimpulan yang telah didapatkan dari proses pengolahan data yang dilakukan selama penelitian dilakukan, sekaligus memberikan saran untuk kemudian dapat menjadi evaluasi dalam proses pengambilan data dikemudian hari agar lebih baik.

Untuk membantu dalam perhitungan, analisis dan pembahasan diperlukan beberapa teori penunjang yang dibutuhkan sebagai berikut :

\section{Ground Vibration}

Getaran tanah (Ground Vibration) merupakan suatu gelombang yang bergerak didalam tanah yang disebabkan karena adanya sumber energi. (Bieniawski,1989 dalam Maryura, 2014). Sumber getaran tersebut dapat berasal dari alam ataupun dari adanya aktivitas manusia, salah satu diantaranya yang disebabkan oleh alam merupakan gempa bumi sedangkan yang disebabkan oleh aktivitas manusia merupakan seperti kegiatan peledakan. Suatu getaran tanah pada tingkat tertentu dapat menyebabkan kerusakan struktur di sekitar lokasi peledakan. Karena itu dalam melakukan suatu kegiatan peledakan harus dilakukan dengan prosedur yang baik dan aman bagi lingkungan sekitar. Getaran tanah yang disebabkan oleh kegiatan peledakan dipengaruhi oleh dua faktor utama yakni faktor yang dapat dikontrol serta tidak dapat dikontrol. Yang dimaksud disini yang tidak dapat dikontrol merupakan karena faktor geologi dan geomekanik batuan dan pengaruh air/alam sedangkan faktor yang dapat dikontrol dapat berupa jumlah bahan peledak, jarak dari lokasi peledakan, geometri peledakan, dan juga bahan peledak yang digunakan (Hajihassani, 2015). Tingkat getaran akibat peledakan dapat diprediksi, hal tersebut dapat dimanfaatkan untuk menentukan jarak aman pembangunan infrastruktur agar tidak mengalami kerusakan struktur akibat peledakan. Untuk memprediksi getaran, dapat dilakukan melalui 2 metode, yaitu menggunakan hukum scaled distance dan peak particle velocity. Hukum scaled distance merupakan perbandingan antara jarak dan isian bahan peledak yang digunakan. Dengan metode ini, maka dapat ditentukan berapa jarak aman dari pusat ledakan. Menurut Langefors dan Kiehlstrom besarnya scale distance adalah:

Keterangan :

$$
\mathrm{SD}=\frac{\mathrm{R}}{\mathrm{Q}^{0,5}}
$$

$\mathrm{SD}:$ Scale distance $(\mathrm{kg} / \mathrm{m})$

$\mathrm{R}$ : Jarak titik pengukuran (m)

Q : Bahan peledak maksimum per waktu tunda $(\mathrm{kg})$

Dari nilai scaled distance yang didapat, maka kecepatan maksimal untuk menghitung besarnya getaran pada suatu lokasi dapat diketahui melalui persamaan peak particle velocity besarnya PPV dinyatakan dengan persamaan :

PPV : peak particle velocity $(\mathrm{mm} / \mathrm{s})$

$$
\mathrm{PPV}=\mathrm{k} \times \mathrm{SD}-\mathrm{m}
$$

$\mathrm{SD}$ : scale distance

$\mathrm{K}$ : sesuai dengan grafik hasil pengolahan

$\mathrm{M}$ : sesuai dengan grafik hasil pengolahan

\section{Prediktor Analisis Getaran}

1. Getaran dengan Prediktor Simangunsong, 2015

Dalam analisis getarannya, prediktor (Simangunsong, 2015) memprediksikan getaran peledakan dengan mempertimbangkan data geologi dan geoteknik batuan dengan menggunakan rumus :

$$
\mathrm{PPV}=\mathrm{k}\left[\left(1+\cos \theta_{i}+N_{c}\right) \frac{R}{\sqrt{Q}}\right]^{-b}
$$

Keterangan:

$$
\begin{array}{ll}
\mathrm{k} & =\text { Koefisien Peluruhan } \\
\theta_{i} & =\text { Kemiringan Lereng }(0) \\
\mathrm{N}_{\mathrm{c}} & =\text { Jumlah lapisan batuan yang akan diledakkan } \\
\mathrm{R} & =\text { Jarak pengukuran }(\mathrm{m})
\end{array}
$$


$\mathrm{Q} \quad=$ Berat bahan peledak $(\mathrm{kg})$

$\mathrm{B} \quad=$ Site exponent

2. Prediksi Getaran dengan Prediktor IS 6922, 1973

Dalam prediksi getaran dengan prediktor IS 6922, 1973 memprediksikan getaran tanah dengan anggapan bahwa batuan yang diluruhkan dengan menggunakan peledakan memiliki potensi merusak yang berarah mengelilingi struktur pada tambang bawah tanah dengan menggunakan rumus :

Keterangan:

$$
\mathrm{PPV}=\mathrm{k}\left[\frac{Q^{2 / 3}}{R}\right]^{1,25}
$$

$\mathrm{k}=$ Koefisien Peluruhan

$\mathrm{R}=$ Jarak pengukuran $(\mathrm{m})$

$\mathrm{Q}=$ Berat bahan peledak $(\mathrm{kg})$

3. Prediksi Getaran dengan Prediktor Ambraseys and Hendron, 1968

Dalam penentukan getaran tanah yang direkomendasikan dengan prediktor (Ambraseys and Hendron, 1968) dengan menggunakan rumus :

$$
\mathbf{P P V}=\mathbf{k}\left(\frac{\mathbf{R}}{\mathbf{Q}^{\frac{1}{3}}}\right)^{-\mathbf{b}}
$$

Keterangan:

$$
\begin{array}{ll}
\mathrm{k} & =\text { Koefisien Peluruhan } \\
\mathrm{R} & =\text { Jarak pengukuran }(\mathrm{m}) \\
\mathrm{Q} & =\text { Berat bahan peledak }(\mathrm{kg}) \\
\mathrm{b} & =\text { site exponent }
\end{array}
$$

\section{Hasil Penelitian dan Pembahasan}

\section{Data Hasil Penelitian}

Dari hasil pengukuran getaran tanah akan didapatkan beberapa variabel data, diantaranya Peak Particle Velocity (PPV) dengan arah gelombang transversal, vertikal serta longitudinal. Adapun data Peak Particle Velocity hasil pengukuran dapat dilihat pada Tabel 1

Tabel 1 Jarak, Berat Bahan Peledak dan Getaran Peledakan Hasil Pengukuran

\begin{tabular}{lrrrrrr}
\hline \multirow{2}{*}{ Lokasi } & \multicolumn{2}{c}{ Jarak $(\mathrm{m})$} & \multicolumn{2}{c}{ Weight $(\mathrm{kg})$} & \multicolumn{2}{c}{ PPV $(\mathrm{mm} / \mathrm{s})$} \\
\cline { 2 - 7 } & Minimum & Maksimum & Minimum & Maksimum & Minimum & Maksimum \\
\hline Inlet KCIC & 20,4 & 227,6 & 4,0 & 50,8 & 0,4 & 30,9 \\
Outlet KCIC & 63,0 & 213,0 & 14,4 & 41,6 & 0,6 & 14,6 \\
\hline
\end{tabular}

Faktor-Faktor yang Mempengaruhi Tingkat Getaran Hasil Peledakan

Beberapa faktor yang mempengaruhi tingkat getaran peledakan diantaranya yakni jarak, muatan bahan peledak, jenis gelombang getar dan konstanta peledakan (Permana, 2019)

1. Jarak

Jarak pengamatan yang dilakukan dari titik peledakan akan mempengaruhi nilai PPV nya di mana semakin jauhnya jarak pengamatan dari titik peledakan maka nilai PPV nya juga akan semakin menurun. (Permana, 2019) adapun data pengaruh jarak terhadap getaran dapat dilihat pada Gambar 1 dan Tabel 2

Tabel 2 Tingkat Hubungan Jarak dan PPV

\begin{tabular}{cccc}
\hline Lokasi & $\mathrm{R}^{2}$ & $\mathrm{R}$ & Tingkat Hubungan \\
\hline Inlet KCIC & 0,5209 & 0,72 & Kuat \\
Outlet KCIC & 0,3331 & 0,58 & Cukup \\
\hline
\end{tabular}




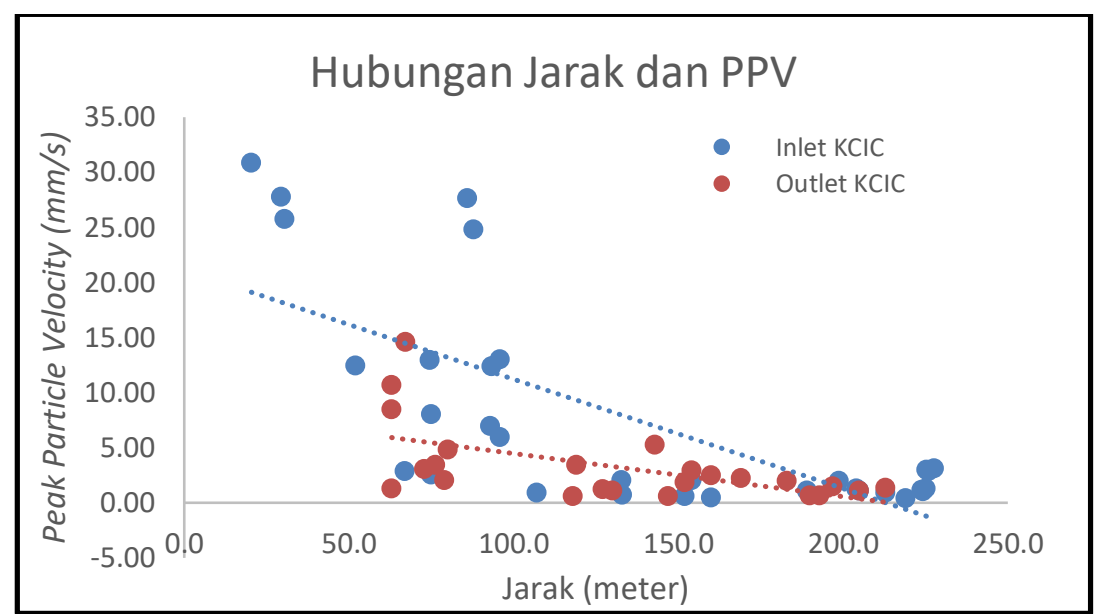

Gambar 1 Grafik Hubungan Jarak dan PPV

Dalam penentuan lokasi peledakan, harus memperhatikan jarak aman dari daerah peledakan, hal ini karena jarak mempengaruhi getaran dan apabila tidak perhatikan maka akan mengganggu keamanan dan kenyaman bagi pekerja ataupun masyarakat yang ada di sekitar area peledakan.

2. Muatan bahan peledak

Berbeda halnya dengan jarak, berat bahan peledak sendiri merupakan faktor utama yang mempengaruhi besarnya PPV di mana semakin banyaknya bahan peledak yang digunakan maka akan menyebabkan nilai PPV semakin besar/meningkat. (Permana, 2019) adapun besaran pengaruh PPV yang dihasilkan akibat dari penggunaan berat bahan peledak dapat dilihat pada Gambar 2 dan Tabel 3

Tabel 3 Tingkat Hubungan Berat Bahan Peledak dan PPV

\begin{tabular}{cccc}
\hline Lokasi & $\mathrm{R}^{2}$ & $\mathrm{R}$ & Tingkat Hubungan \\
\hline Inlet KCIC & 0,0447 & 0,21 & Rendah \\
Outlet KCIC & 0,1248 & 0,35 & Rendah \\
\hline
\end{tabular}

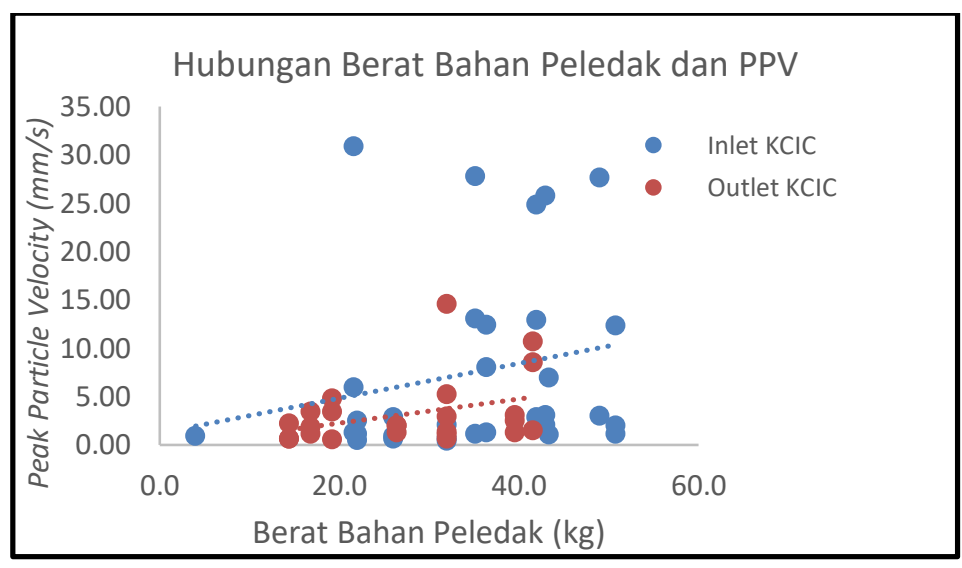

Gambar 2 Grafik Hubungan Berat Bahan Peledak dan PPV

Dalam penggunaan bahan peledak, banyaknya bahan peledak yang meledak secara bersamaan harus diperhatikan, karena jika terlalu banyak akan menyebabkan getaran yang besar dan bisa melewati ambang maksimum yang telah ditentukan. Sehingga apabila adanya getaran yang melebihi nilai ambang batasnya perlu adanya kajian dalam penentuan bahan peledak yang digunakan dalam waktu tunda yang digunakan.

3. Jenis gelombang getar

Berdasarkan Tabel 4 diperlihatkan nilai peluruhan yang mempengaruhi untuk bagian 
Inlet dan Outlet.

Tabel 4 Data Koefisien Peluruhan dan Site Exponent Peak Particle Velocity

\begin{tabular}{crrrrrrrrrrrr}
\hline \multirow{2}{*}{ Lokasi } & \multicolumn{3}{c}{ Transversal } & \multicolumn{3}{c}{ Vertikal } & \multicolumn{3}{c}{ Longitudinal } & \multicolumn{3}{c}{ Summary } \\
\cline { 2 - 13 } & $\mathrm{k}$ & $\mathrm{e}$ & $\mathrm{R}^{2}$ & $\mathrm{k}$ & $\mathrm{e}$ & $\mathrm{R}^{2}$ & $\mathrm{k}$ & $\mathrm{e}$ & $\mathrm{R}^{2}$ & $\mathrm{k}$ & $\mathrm{e}$ & $\mathrm{R}^{2}$ \\
\hline Inlet KCIC & 690,70 & 1,94 & 0,61 & 247,13 & 1,61 & 0,76 & 197,99 & 1,47 & 0,65 & 520,43 & 1,68 & 0,74 \\
Outlet KCIC & 24,99 & 0,97 & 0,31 & 90,02 & 1,29 & 0,39 & 33,49 & 0,95 & 0,40 & 88,52 & 1,17 & 0,44 \\
\hline
\end{tabular}

4. Konstanta Peluruhan dan Site Exponent

Konstanta peluruhan sangat dipengaruhi oleh tingkat peredaman batuan, semakin besarnya tingkat peredaman maka nilai konstanta peluruhannya akan semakin kecil. Semakin besar nilai K maka nilai e akan semakin besar juga, hal ini disebabkan karena keduanya yang saling berhubungan. Dapat dilihat pada Gambar 3

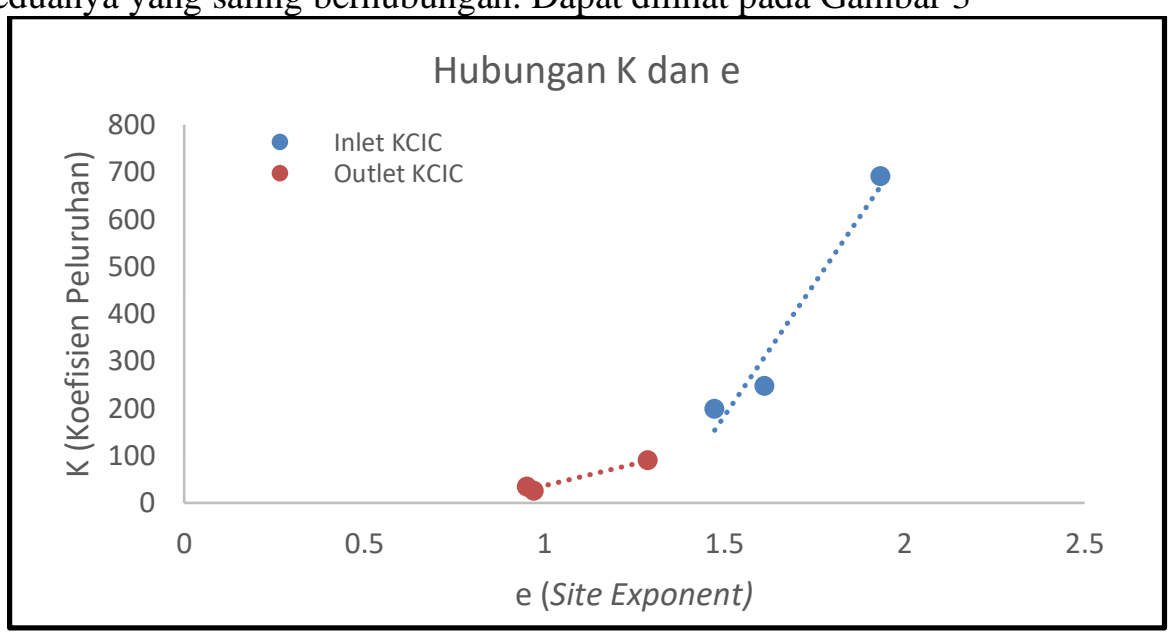

Gambar 3 Grafik Konstanta Peluruhan dan Site Exponent

Tabel 5 Tingkat Hubungan Konstanta Peluruhan dan Site Exponent

\begin{tabular}{cccc}
\hline Lokasi & $\mathrm{R}^{2}$ & $\mathrm{R}$ & Tingkat Hubungan \\
\hline Inlet KCIC & 0,9568 & 0,98 & Sangat Kuat \\
Outlet KCIC & 0,9702 & 0,98 & Sangat Kuat \\
\hline
\end{tabular}

Berdasarkan Tabel 5, bahwa konstanta peluruhan dan site exponent sangat mempengaruhi getaran peledakan dimana kedua konstanta tersebut saling berikatan sangat kuat.

\section{PPV Prediksi Berdasarkan Prediktor}

Berdasarkan konstanta peluruhan dan site exponent yang didapatkan, dilakukan prediksi getaran tanah untuk mengetahui prediktor yang memodelkan data getaran paling mendekati nilai getaran aktualnya. Dapat dilihat pada Tabel 6

Tabel 6 PPV Prediksi Berdasarkan Prediktor

\begin{tabular}{rrrrrrr}
\hline No & Lokasi & PVS Aktual & PPV Regresi Power & PPV Simangunsong & PPV IS 6922 & PPV Ambraseys \\
\hline 1 & Inlet & 0,90 & 0,65 & 0,20 & 4,80 & 0,44 \\
2 & Inlet & 1,28 & 1,41 & 0,44 & 13,50 & 0,52 \\
3 & Inlet & 12,44 & 14,02 & 4,38 & 74,52 & 5,13 \\
4 & Inlet & 8,06 & 7,58 & 2,37 & 47,15 & 2,77 \\
5 & Inlet & 0,40 & 1,13 & 0,35 & 11,09 & 0,43 \\
6 & Inlet & 0,74 & 2,60 & 0,81 & 20,69 & 0,99 \\
7 & Inlet & 2,07 & 2,03 & 0,64 & 17,23 & 0,77 \\
8 & Inlet & 0,47 & 1,39 & 0,44 & 12,02 & 0,59
\end{tabular}




\begin{tabular}{|c|c|c|c|c|c|c|}
\hline No & Lokasi & PVS Aktual & PPV Regresi Power & PPV Simangunsong & PPV IS 6922 & PPV Ambraseys \\
\hline 9 & Inlet & 2,53 & 4,97 & 1,55 & 30,99 & 2,09 \\
\hline 10 & Inlet & 1,12 & 0,92 & 0,29 & 8,82 & 0,39 \\
\hline 11 & Inlet & 0,61 & 1,75 & 0,55 & 14,73 & 0,70 \\
\hline 12 & Inlet & 2,90 & 6,91 & 2,16 & 41,01 & 2,78 \\
\hline 13 & Inlet & 0,91 & 0,99 & 0,31 & 9,66 & 0,40 \\
\hline 14 & Inlet & 12,37 & 6,94 & 2,17 & 47,31 & 2,31 \\
\hline 15 & Inlet & 1,12 & 2,13 & 0,66 & 19,60 & 0,71 \\
\hline 16 & Inlet & 2,02 & 1,96 & 0,61 & 18,41 & 0,65 \\
\hline 17 & Inlet & 30,85 & 43,49 & 13,59 & 155,37 & 18,42 \\
\hline 18 & Inlet & 5,97 & 3,24 & 1,01 & 22,45 & 1,37 \\
\hline 19 & Inlet & 1,28 & 0,77 & 0,24 & 7,73 & 0,33 \\
\hline 20 & Inlet & 25,75 & 39,25 & 12,27 & 166,12 & 13,71 \\
\hline 21 & Inlet & 2,06 & 3,35 & 1,05 & 26,55 & 1,17 \\
\hline 22 & Inlet & 3,10 & 1,35 & 0,42 & 13,52 & 0,47 \\
\hline 23 & Inlet & 24,82 & 6,55 & 2,05 & 43,56 & 2,30 \\
\hline 24 & Inlet & 12,94 & 8,61 & 2,69 & 53,39 & 3,03 \\
\hline 25 & Inlet & 2,89 & 1,34 & 0,42 & 13,37 & 0,47 \\
\hline 26 & Inlet & 13,05 & 4,88 & 1,53 & 33,72 & 1,80 \\
\hline 27 & Inlet & 27,77 & 35,48 & 11,09 & 147,81 & 13,11 \\
\hline 28 & Inlet & 1,16 & 1,18 & 0,37 & 11,68 & 0,43 \\
\hline 29 & Inlet & 27,66 & 7,75 & 2,42 & 50,98 & 2,61 \\
\hline 30 & Inlet & 2,98 & 1,54 & 0,48 & 15,26 & 0,52 \\
\hline 31 & Inlet & 6,95 & 6,14 & 1,92 & 41,78 & 2,14 \\
\hline 32 & Inlet & 1,06 & 1,40 & 0,44 & 13,88 & 0,49 \\
\hline 1 & Outlet & 2,48 & 1,33 & 0,59 & 2,01 & 0,70 \\
\hline 2 & Outlet & 3,04 & 3,58 & 1,59 & 5,75 & 1,89 \\
\hline 3 & Outlet & 1,26 & 4,67 & 2,07 & 7,63 & 2,46 \\
\hline 4 & Outlet & 0,57 & 1,60 & 0,71 & 2,68 & 0,77 \\
\hline 5 & Outlet & 4,81 & 6,10 & 2,70 & 11,15 & 2,94 \\
\hline 6 & Outlet & 3,43 & 6,10 & 2,70 & 11,15 & 2,94 \\
\hline 7 & Outlet & 1,97 & 1,03 & 0,46 & 1,34 & 0,61 \\
\hline 8 & Outlet & 2,03 & 1,57 & 0,69 & 2,10 & 0,93 \\
\hline 9 & Outlet & 1,28 & 0,88 & 0,39 & 1,14 & 0,52 \\
\hline 10 & Outlet & 1,47 & 1,25 & 0,55 & 1,95 & 0,63 \\
\hline 11 & Outlet & 8,50 & 4,84 & 2,15 & 8,26 & 2,46 \\
\hline 12 & Outlet & 10,70 & 2,00 & 0,88 & 3,21 & 1,01 \\
\hline 13 & Outlet & 1,11 & 1,98 & 0,88 & 3,34 & 0,97 \\
\hline 14 & Outlet & 3,46 & 4,98 & 2,21 & 8,90 & 2,43 \\
\hline 15 & Outlet & 1,85 & 2,60 & 1,15 & 4,45 & 1,27 \\
\hline 16 & Outlet & 2,24 & 0,90 & 0,40 & 1,20 & 0,52 \\
\hline 17 & Outlet & 0,63 & 2,86 & 1,27 & 4,13 & 1,65 \\
\hline 18 & Outlet & 0,64 & 1,27 & 0,56 & 1,74 & 0,73 \\
\hline 19 & Outlet & 1,37 & 1,43 & 0,63 & 2,03 & 0,80 \\
\hline 20 & Outlet & 14,60 & 2,92 & 1,30 & 4,34 & 1,64 \\
\hline 21 & Outlet & 5,26 & 1,84 & 0,81 & 2,64 & 1,03 \\
\hline 22 & Outlet & 1,09 & 2,23 & 0,99 & 3,62 & 1,13 \\
\hline 23 & Outlet & 0,65 & 1,43 & 0,63 & 2,25 & 0,73 \\
\hline 24 & Outlet & 2,92 & 1,83 & 0,81 & 2,93 & 0,93 \\
\hline
\end{tabular}

Dalam penggunaan prediktor untuk penentuan prediksi getaran, dalam Gambar 4 memperlihatkan perbandingan antara PPV aktual dengan PPV prediksi. Dalam gambar diperlihatkan bahwa semua prediktor memiliki perbedaan dengan data aktual yang kecil, kecuali pada prediktor IS 6922 meskipun pada Tabel 7 prediktor tersebut memiliki nilai koefisien korelasi tertinggi, namun pada dasarnya nilai PPV prediksi yang dihasilkan sangat jauh berbeda dengan data PPV aktual yang didapatkan.

Tabel 7 Tingkat Hubungan PPV Prediksi dan PPV Aktual 


\begin{tabular}{|c|c|c|c|c|c|c|c|c|c|c|c|c|}
\hline \multirow{2}{*}{ Lokasi } & \multicolumn{3}{|c|}{ Regresi Power } & \multicolumn{3}{|c|}{ Simangunsong } & \multicolumn{3}{|c|}{ IS 6922} & \multicolumn{3}{|c|}{ Ambraseys } \\
\hline & $\mathrm{R}^{2}$ & $\mathrm{R}$ & $\begin{array}{l}\text { Tingkat } \\
\text { Hubungan }\end{array}$ & $\mathrm{R}^{2}$ & $\mathrm{R}$ & $\begin{array}{l}\text { Tingkat } \\
\text { Hubungan }\end{array}$ & $\mathrm{R}^{2}$ & $\mathrm{R}$ & $\begin{array}{l}\text { Tingkat } \\
\text { Hubungan }\end{array}$ & $\mathrm{R}^{2}$ & $\mathrm{R}$ & $\begin{array}{l}\text { Tingkat } \\
\text { Hubungan }\end{array}$ \\
\hline $\begin{array}{l}\text { Inlet } \\
\text { KCIC }\end{array}$ & $\begin{array}{l}0,66 \\
34\end{array}$ & $\begin{array}{l}0, \\
81\end{array}$ & Sangat Kuat & $\begin{array}{l}0,66 \\
34\end{array}$ & $\begin{array}{l}0 \\
81\end{array}$ & Sangat Kuat & $\begin{array}{l}0,72 \\
29\end{array}$ & $\begin{array}{l}0 \\
85\end{array}$ & Sangat Kuat & $\begin{array}{l}0,64 \\
02\end{array}$ & $\begin{array}{l}0 \\
80\end{array}$ & Sangat Kuat \\
\hline $\begin{array}{l}\text { Outlet } \\
\text { KCIC }\end{array}$ & $\begin{array}{l}0,49 \\
39\end{array}$ & $\begin{array}{l}0, \\
70\end{array}$ & Kuat & $\begin{array}{l}0,49 \\
39\end{array}$ & $\begin{array}{l}0, \\
70\end{array}$ & Kuat & $\begin{array}{l}0,01 \\
01\end{array}$ & $\begin{array}{l}0, \\
10\end{array}$ & $\begin{array}{l}\text { Sangat } \\
\text { Rendah }\end{array}$ & $\begin{array}{l}0,48 \\
32\end{array}$ & $\begin{array}{l}0, \\
70\end{array}$ & Kuat \\
\hline
\end{tabular}

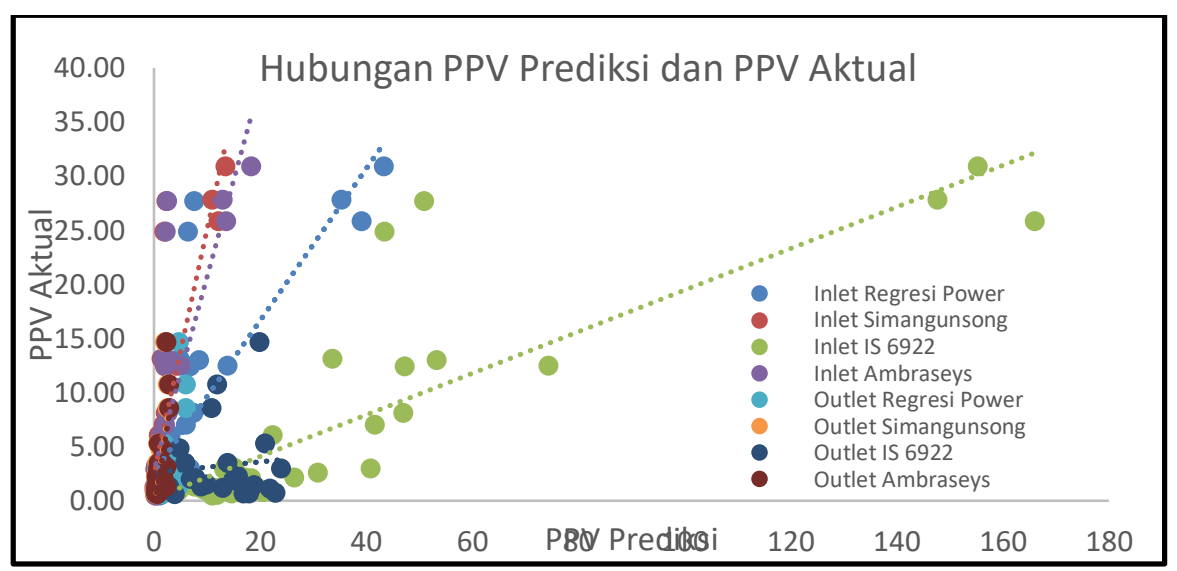

Gambar 4 Hubungan PPV Prediksi dan PPV Aktual

\section{Kesimpulan}

Kesimpulan yang dapat diambil dari hasil penelitian yang dilakukan adalah sebagai berikut :

1. Parameter yang mempengaruhi tingkat getaran tanah pada penelitian ini yakni: jarak, dengan tingkat hubungan cukup hingga kuat, berat bahan peledak memiliki tingkat hubungan yang rendah, jenis gelombang getar dan konstanta peluruhan serta site exponent dengan tingkat hubungan sangat kuat.

2. Hasil dari prediksi getaran dengan berbagai prediktor didapatkan bahwa semua prediktor memiliki perbedaan dengan data aktual yang kecil, kecuali pada prediktor IS 6922 meskipun prediktor tersebut memiliki nilai koefisien korelasi tertinggi, namun pada dasarnya nilai PPV prediksi yang dihasilkan sangat jauh berbeda dengan data PPV aktual yang didapatkan. Data prediksi yang dihasilkan didapatkan bahwa model PPV hasil prediksi oleh regresi power memiliki nilai yang sangat mendekati dengan nilai PPV aktual dibandingkan dengan prediksi oleh model atau prediktor lain.

\section{Daftar Pustaka}

[1] Ambraseys, et all. 1968 "Dynamic Behavior of Rock Masses" London.

[2] Hajihassani,Mohsen. 2015. "Blast-Induced Air and Ground Vibration Prediction: a Particleswarm Optimization-Based Artificial Neural Network Approach". Construction Research Alliance, Universiti Teknologi Malaysia

[3] Hoyle,Aaron. 2020. "Relationship Between Specific Weight of Spring Barley and Malt Quality". Scotland: Edinburgh Campus.

[4] IS 6922, 1973 "Criteria for Safety and Design Structures Subject to Underground Blast” New Delhi, India

[5] Kumar, Ranjan, 2016 "Determination of blast-induced ground vibration equations for rocks using mechanical and geological properties" Mumbai, India

[6] Kuzu, 2008. "The Importance of Site-Spesific Characters in Prediction Models for Blastinduced Ground Vibrations" Soil Dynamics and Earthquake Engineering

[7] Maryura., dkk. 2014. "Kajian Pengurangan Tingkat Getaran Tanah (Ground Vibration Level) 
pada Operasi Peledakan Interburden B2-C Tambang Batubara Air Laya PT. Bukit Asam (Persero)" Tanjung Enim

[8] Permana, A.R. 2019. "Kajian Pengurangan Getaran Tanah (Ground Vibration) Pada Peledakan Overburden Tambang Batubara di PT. Artamulia Tata Pratama Site Tanjung Belit Provinsi Jambi”. Jurusan Teknik Pertambangan, Fakultras Teknik, Universitas Negeri Padang.

[9] Rai, Made Astawa,dkk. 2013. "Mekanika Batuan". Bandung: Penerbit ITB.

[10] Simangunsong, 2015 "Effect Of Bedding Plane On Prediction Blast-Induced Ground Vibration In Open Pit Coal Mines" Institut Teknologi Bandung: Bandung.

[11] Sunwoo, C. and Hwang S. 2001 "Correlation Of Rock Mass Classification Methods In Korean Rock Mass" Beijing, China.

[12] Zhang, et all. "Quantitative Assessments Of The Correlations Between Rock Mass Rating (RMR) And Geological Strength Index (GSI)" Jiangsu, China. 